\title{
Disfigurement: Psychosocial Impact and Coping
}

\author{
Sreedhar Krishna*
}

Faculty of Medicine, Imperial College London, UK

\begin{abstract}
Using the prism of skin disease, this short letter examines the overall impact that disfigurement can have on sufferers' lives. Often trivialised by health professionals and laypeople alike, the common misconception that skin disease is not 'serious' is challenged. Looking in turn at the overall psychosocial impact and psychiatric co-morbidities, the effects of stigmatisation are examined as well as the coping strategies to which patients turn. By providing a brief overview of the factors that must be considered in clinic, the worthiness of adopting a holistic approach to one's patients is emphasised.
\end{abstract}

\section{"Disfigurement is not being able to wait at the bus stop at 4 pm because the school kids call you freak. Disfigurement is not going swimming because of people staring. Disfigurement is Jerry Springer rather than the park in July" [1].}

Mr. H.L., vitiligo sufferer

Disfigurement is more formally defined as a state in which one's appearance is deeply and persistently harmed medically, as from a disease, birth defect or wound. Medical professionals encounter the 'disfigured' daily; the plastic surgeon performs contracture surgery for burn survivors while dermatologists prescribe calcipotriene for psoriasis. Truly efficient treatment, however, necessitates a more holistic approach. Skin disease is often trivialised by healthcare professionals and laypeople alike [2], but unlike internal pathology, external flaws are often immediately apparent to others. Skin disease can terribly impact quality of life, self-esteem and body image. Moreover, the degree of medical severity often bears little relation to the psychological morbidity experienced by sufferers $[3,4]$. This short essay aims to provide an overview of the psychosocial sequelae of disfigurement. Just as the psyche seeks equilibrium $[5,6]$ so does the sufferer; this is strived for by various coping mechanisms, which in turn will be discussed.

\section{PSYCHOSOCIAL IMPACT}

Among its myriad biological functions (e.g. thermoregulation, sensation, excretion), skin plays a key role in communication: it is the boundary between self and the environment, serving as the point of contact when meeting strangers. Skin can communicate to others one's own response to stimuli, be they physiological (i.e. peripheral cyanosis in the cold) or psychological (i.e. blushing upon embarrassment). Dermatological disorders can especially impair tactile communication, bodily interaction and sexual relations [7].

Sufferers of skin disease have direct access to their skin lesions and, in this regard, can directly influence the progress

\footnotetext{
*Address correspondence to this author at Faculty of Medicine, Imperial College London, South Kensington Campus, London, SW7 2AZ, UK; Tel: +44208908 3723; Fax: +44 208968 1947;
}

E-mail: sreedhar.krishna04@imperial.ac.uk of their condition. An eczema patient may be more motivated to apply emollient (since they can see the benefit of treatment themselves) as compared to those involved in post-MI physiotherapy for example. Since the majority of skin disease is accompanied by pain and discomfort, it can be difficult to differentiate between the physiological and psychosocial impact of the condition. The psychological facet of dermatological conditions has long been recognised $[8,9]$ although the link between skin disease and psychosocial problems has only been investigated recently [10].

To reiterate, skin disease is often manifest by lesions that are obvious to others. The public nature of the condition can damage patients' sense of autonomy, as they cannot control with whom they share their diagnosis. Disappointingly, skin disease is often associated with lack of hygiene and contagion [7, 11]. Such feelings can influence others to minimise interaction with the patient, concomitantly stigmatising and leading to social isolation [12]. The potential repercussions of skin disease cannot be underestimated; an article in the Journal of Health Psychology reports that $25 \%$ of patients with severe psoriasis have wished they were dead. Perhaps even more worrisome, $8 \%$ of those surveyed felt that life was currently not worth living [13].

Most common diseases are characterised by flares and remissions. Emotional stress has been shown to exacerbate many chronic dermatoses and can initiate a vicious cycle referred to as the "itch-scratch cycle" [14]. However, patients may attribute exacerbations to biologically implausible factors which can lead to avoidance behaviour, with the patient reinforcing their own social isolation [15]. Misinformation is rife among dermatology patients: a pervasive misconception is that 'white' foods cause vitiligo; assenting to such a belief would presumably lead to dietary insufficiency with as well as long-term sequelae. When patients do try to participate in communal activities of daily living, negative reactions from others can precipitate even greater withdrawal. Furthermore, patients often feel that they have fallen short of their image of ideal self, with an ensuing sense of guilt. 
It is commonly suggested that individuals whose appearance significantly deviates from the perceived norm have a more defined sense of self, leading to a greater pressure to comply with social standards. This pressure has important ramifications, affecting relationships and hobbies [16], quality of life [17] as well as career aspirations [18].

Research on people with skin disease points towards depression [19], negative body image [20], relationship difficulties [4], as well as a general reduction in quality of life [21]. Likewise, literature shows that sufferers experience increased levels of psychological and social distress [22], poor self body image and lower esteem than the general population [23]. Leary et al. hypothesise that the degree of social anxiety experienced correlates with the individual's confidence in their ability to manage the impression they make on others [24].

A study on skin disease outpatients investigated the impact that their conditions had made on them [25]. They complained of relationship and employment difficulties as well as poor self-esteem. Supporting this, a British survey of acne patients reports higher levels of unemployment as compared to control participants [26].

While literature points towards the magnitude of psychosocial impact of skin disease, it is important to adopt a balanced perspective. Individual variation means that just as for some, skin disease is genuinely debilitating, for others the condition can be largely irrelevant. Highlighting this, Kalick's work on individuals living with a port wine stain seeking laser therapy found no evidence of elevated psychological distress [27].

\section{PSYCHIATRIC COMORBIDITY}

The psychiatric co-morbidity of skin disease is a vital index of the overall associated disability [28, 29]. It has been established that at least $30 \%$ of dermatology patients suffer from significant psychiatric co-morbidity. Interestingly, Picardi et al. suggest that untreated co-morbid psychiatric disorders may adversely affect the response of the dermatological disorder to prescribed therapies [30]. This data alone could vindicate practitioners of a more holistic brand of medicine. Stress-related neuro-immunomodulation may affect the course of viral infections, such as HPVassociated warts and possibly cutaneous malignancies. Chronic dermatoses such as psoriasis, atopic eczema and acne share a common strong link between their psychiatric and psychosocial components [31]. Dermatological disease is most prominently associated with mood disorders such as major depression as well as anxiety disorders.

The interaction between skin and the psyche begins in early development and thus it is important to assess psychiatric pathology in the dermatology patient from a developmental perspective. Notably, the ectodermal origins common to the epidermis and central nervous system suggest that perhaps some psychiatric and dermatologic disorders share a common origin. As alluded to earlier, skin plays an integral role in communication; in addition, it is key to early attachment. The earliest interaction between mother and child occurs through the body, primarily via touch. Skin disorders during infancy may result in a decrease in 'tactile nurturance' such as holding, massage and hugging that the infant receives from the caregiver [32]. Constant clinging or skin-to-skin contact is a primary factor in cementing the maternal-infant bond while failure to develop this initial bond is linked to depression in later life. Inadequate contact during early development may also predispose to subsequent body image problems [33].

Ordinarily, adolescence is a period associated with increased incidence of depression and body image disorders. Thus, skin disease afflicting patients of this fragile age-group can be especially devastating. Synergistically, these factors can predispose towards serious adverse outcomes such as suicide in teenage acne patients [34].

\section{STIGMA}

Dermatology patients often ascribe their main difficulties arise to others' reactions to their disease rather than the disease itself [35]. Perceptions of stigmatisation are common in this cohort with $26 \%$ of psoriasis patients experiencing at least one incident when someone made a concerted effort not to touch them because of their psoriasis [36]. Ginsburg and Link conducted an in-depth study of stigmatisation in people with psoriasis [37]. They asked patients to complete a questionnaire enquiring about their feeling towards psoriasis and beliefs about others' reaction to the condition. Factor analysis indicated that beliefs of stigmatisation could be stratified into various dimensions:

1. Anticipation of rejection - e.g. "I feel physically unattractive and sexually unattractive when the psoriasis is bad."

2. Feelings of being flawed - e.g. "I believe that others think psoriasis patients are dirty."

3. Sensitivity to opinions of others - e.g. "I feel outcasted because of my psoriasis."

4. $\quad$ Secretiveness - e.g. "I do my utmost to hide my psoriasis from family members that I do not live with."

5. Positive dimensions - e.g. "If my child were afflicted by psoriasis, I think he or she would develop to his or her potential just as though he or she did not have it."

These results were reliably reproduced by a German version of this questionnaire [38].

Moreever, work on HIV-related stigma has revealed four individual dimensions which may be relevant in disfigurement:

1. Interpersonal interaction - This refers to the stigma and discrimination experienced in the context of social relationships. Disfigurement commonly leads to social exclusion and withdrawal. Exclusion and withdrawal are not only experienced through the absence of friends and relatives; rather, they are often manifested as a 'lack of interest,' and curiosity, ridicule and gossip. Previous associates may shun the patient for fear that they may 'catch' their psoriasis.

2. Structural discrimination - The second stigma domain reaches beyond direct social interaction. Stigma and discrimination are also experienced as through imbalances and justices inherent in social structures. The patient perceived as disfigured may have to deal with the negative beliefs of others. 
3. Enacted stigma - Individuals who are viewed as disfigured often face discriminatory behaviours. An example of a discriminatory behaviour is the exclusion of psoriasis sufferers at public swimming baths.

4. Layered stigma - By the exposed nature of dermatoses, the dermatology patient is often unable to control who he shares his diagnosis with. However, for those who have fairly obscure lesions, the decision to disclose one's diagnosis is often traumatic. Patients may consequently try to explain away their lesion with falsities leading to a greater personal burden.

While the last two domains are directly observable, the first two are not.

Perceptions and beliefs such as these are not easily attributable to over-sensitivity. Kleck and Strenta have shown that people with disfigurement do indeed encounter stigmatisation [39]. In their study, a confederate of the experimenters was produced; reactions were compared between when the confederate had an unblemished face or an artificial scar applied to the cheek. Subjects were prone to judge the confederate's behaviour negatively when the scar had been applied. Rumsey et al. have taken a more subtle approach towards investigating stigma. Make-up was applied so it seemed that a person waiting at a pedestrian crossing had either a port-wine stain to one side of the face, an accident (indicated by a bandage), or had an unblemished face. Other people waiting at the light stood furthest away from the confederate when he had a port wine stain, and were less likely to stand on the affected side [40]. Most tellingly, Houston and Bull found that people are likely to avoid sitting beside someone whose appearance has been changed due to port wine staining [41].

\section{COPING}

While many people living with skin conditions adapt well to their condition, there is also a tendency towards maladaptive coping strategies and significant psychosocial as well as physical distress [42]. Coping is an umbrella term encompassing the various strategies (cognitive, behavioural and emotional) used to manage specific stressors. Lazarus' transactional theory is currently the predominant model of coping [43]. This model suggests that by a process of primary and secondary appraisal, an individual will draw upon a variety of coping strategies. Weiten and Lloyd have divided coping strategies three-fold [44]:

\section{Problem-focused strategies - e.g. confronting someone staring \\ 2. Emotion-focused strategies - e.g. distracting oneself \\ 3. Appraisal focused strategies - e.g. denial}

In lieu of total social isolation, patients may utilise more subtle safety behaviours - such as turning one's body so as to hide one's perceived worse side in social encounters. Use of such coping mechanisms has been linked to poor adjustment [45]. Individuals may recognise the limitations of adopting such strategies, but regardless feel recourse to do so in place of other mechanisms (such as social proactivity) which would be more demanding of personal resources [46].

\section{MOVING FORWARD}

Cutaneous conditions are rarely life threatening; as such, their impact is often minimised by health professionals. However, such justification involves a transparent petitio principii. Skin disease reaches further than blood tests, Xrays or MRIs can gauge Disfigurement, for many (but not all), can have terrible psychosocial consequences for individuals. Thus, effective care for such patients requires a more holistic and individualised approach, taking into account patient demographics and deontological factors.

Most patients with chronic dermatoses can vividly remember incidents of stigmatisation and persecution. Coping with such traumatic experiences draws upon various mechanisms, some of which are undoubtedly maladaptive. While psychological approaches have been successfully used to treat those affected with skin disorders [47], utilisation of such tools is reactive and not probably practical on a large scale. While, encountering negative reactions may be unavoidable [48], the most cost-effective way to influence public behaviour is by education, appealing by emotive mass-media campaigns. Perhaps in an enlightened environment, the term disfigurement would have purely medical connotations.

\section{REFERENCES}

[1] Quote from Mr. HL. Audio available on request. (Quote used with permission) 2008.

[2] Papadopoulos L, Walker C. Understanding skin problems: Acne, Eczema, Psoriasis and Related Conditions. West Sussex, UK: Wiley 2003.

[3] Ben-Tovim DI, Walker MK. Body image, disfigurement and disability. J Psychosom Res 1995; 39: 283-91.

[4] Robinson E, Rumsey N, Partridge JP. An evaluation of the impact of social interaction skills training for facially disfigured people. $\mathrm{Br}$ J Plast Surg 1996; 49: 281-9.

[5] Giovacchini PL. Erotism and Chaos. J Am Acad Psychoanal Dynam Psychiat 1990; 18: 5-17.

[6] Clarke JJ. Jung and Eastern Thought. Routledge, 1994.

[7] Van Moffaert M. Psychodermatology: an overview. Psychother Psychosom 1992; 58: 125-36.

[8] Wilson A (1863). As cited in Whitlock F.A. Psychophysiological Aspects of Skin Disease. London: WB Saunders Limited 1976.

[9] Engles WD. Dermatologic disorders. Psychosomatics 1982; 23: 1209-19.

[10] Al'Abadie MSK, Kent GG, Gawkrodger DJ. The relationship between stress and the onset and exacerbation of psoriasis and other skin conditions. Br J Dermatol 1994; 130: 199-203.

[11] Kleinman A. The Illness Narratives: Suffering, Healing, and the Human Condition. New York: Basic Books, Inc 1988.

[12] Porter JR, Beuf AH, Lerner A, Nordlund J. The effect of vitiligo on sexual relationships. J Am Acad Dermatol 1990; 22: 221-2.

[13] Rapp SR, Exum ML, Reboussin DM. The physical, psychological and social impact of psoriasis. J Health Psychol 1997; 2: 525-37.

[14] Iyer S, Washenik K, Shupack J. Can psychological stress affect psoriasis? Possible mechanisms. J Clin Dermatol 1988; 1: 21-8.

[15] Papadopoulos L, Walker CJ. Understanding Skin Problems. Chichester: John Wiley \& Sons Ltd 2003.

[16] Porter JR, Beuf AH, Lerner A, Nordlund J. Response to cosmetic disfigurement: patients with vitiligo. Cutis 1987; 39: 493-4.

[17] Lanigan SW, Cotterill JA. Psychological disabilities amongst patients with port-wine stain. Br J Dermatol 1989; 121: 209-15.

[18] Goldberg P, Bernstein N, Crosby R. Vocational development of adolescents with burn injury. Rehabil Counsel Bull 1975; 8: 140-6.

[19] Dungey RK, Busselmeir TJ. Medical and psychosocial aspects of psoriasis. Health Soc Work 1982; 5: 140-7.

[20] Obermeyer A. Psychoses and Disorders of the Skin: Psychocutaneous Medicine. Illinois: Thomas Publishing 1985.

[21] Papadopoulos L, Bor R. Psychological Approaches to Dermatology. Leicester: BPS Books 1999. 
[22] Root S, Kent G, Al-Abadie M. The relationship between disease severity, disability and psychological distress in patients undergoing PUVA treatment. Dermatology 1994; 189: 234-7.

[23] Papadopoulos L, Bor R, Legg C. Coping with the disfiguring effects of vitiligo in adults: a preliminary investigation into the effects of cognitive-behavioural therapy. Br J Med Psychol 1999; 72: 385-96.

[24] Leary MR, Rapp SR, Herbst KC, Exum ML, Feldman SR. Interpersonal concerns and psychological difficulties of psoriasis patients: effects of disease severity and fear of negative evaluation. Health Psychol 1998; 17: 530-6.

[25] Jowett S, Ryan T. Skin disease and handicap: an analysis of the impact of skin conditions. Soc Sci Med 1985; 20: 425-9.

[26] Cunliffe WJ. Unemployment and acne. Br J Dermatol 1986; 115: 386.

[27] Kalick S, Goldwyn R, Noe J. Social issues and body image concerns of port wine stain patients undergoing laser therapy. Lasers Surg Med 1981; 1: 205-13.

[28] Panconesi P. Psychosomatic dermatology. Clin Dermatol 1984; 2: 94-179.

[29] Woodruff PWR, Higgins EM, Du Vivier AWP, Wessely S. Psychiatric illness in patients referred to a dermatology-psychiatry clinic. Gen Hosp Psychiatry 1997; 19: 29-35.

[30] Picardi A, Abeni D, Renzi C, Braga M, Melchi CF, Pasquini P. Treatment outcome and incidence of psychoiatric disorders in dermatologic out-patients. J Eur Acad Dermatol Venerol 2003; 17: $155-9$.

[31] Gupta MA, Gupta AK, Schork NJ, Ellis CN. Depression modulates pruritus perception: a study of pruritus in psoriasis, atopic dermatitis, and chronic idiopathic idiopathic urticaria. Psychosom Med 1994; 56: 36-40.

[32] Walters E. Problems faced by children and families living with visible differences. In: Lansdown R, Rumsey N, Bradbury E, Carr T, Partridge J, Eds. Visibly Diffeent: Coping with Disfigurement. Oxford: Butterworth-Heinemann 1997.

[33] Gupta MA, Gupta AK, Schork NJ, Watteel GN. Perceived touch deprivation and body image: some observations among eating disordered and non-clinical subjects. J Psychosom Res 1995; 39: 459-64.

[34] Cotterill JA, Cunliffe WJ. Suicide in dermatological patients. Br J Dermatol 1997; 137: 246-50.
[35] Rapp S, Feldman S, Exum M, Fleischer A, Reboussin D. Psoriasis causes as much disability as other medical diseases. J Am Acad Dermatol 1999; 41: 401-7.

[36] Gupta M, Gupta A, Watteel G. Perceived deprivation of social touch in psoriasis is associated with greater psychological morbidity: an index of the stigma experience in dermatologic disorders. Cutis 1998; 61: 339-42.

[37] Ginsburg I, Link B. Feelings of stigmatization in patients with psoriasis. J Am Acad Dermatol 1989; 20: 53-63.

[38] Schmidt-Ott G, Jaeger B, Kuensebeck H, Ott R, Lamprecht F. Dimensions of stigmatisation in patients with psoriasis in a questionnaire on experience with skin complaints. Dermatology 1996; 193: 304-10.

[39] Kleck R, Strenta A. Perceptions of the impact of negatively valued physical characteristics on social interaction. J Pers Soc Psychol 1980; 39: 861-73.

[40] Rumsey N, Bull R, Gahagan D. The effect of facial disfigurement on the proxemic behaviour of the general public. J Appl Soc Psychol 1982; 12: 137-50.

[41] Houston B, Bull R. Do people avoid sitting next to someone who is facially disfigured? Eur J Soc Psychol 1994; 24: 279-84.

[42] Walker C, Papadopoulos L. Psychodermatology: The Psychological Impact of Skin Disorders. New York: Cambridge University Press, 2005.

[43] Lazarus R, Folkman S. Stress, Appraisal and Coping. New York: Springer 1984 .

[44] Weiten W, Lloyd MA. Psychology Applied To Modern Life: Adjustment in the $21^{\text {st }}$ Century. Stamford, Connecticut, USA: Thomson Wadsworth 2006.

[45] Rapp SR, Cottrell CA, Leary MR. Social coping strategies associated with quality of life decrements among psoriasis patients. Br J Dermatol 2001; 145: 610-6.

[46] Thompson A. Exploring the Process of Adjustment to Disfigurement with Particular Reference to Vitiligo. Unpublished doctoral thesis 1998 .

[47] Cole WC, Roth HL, Sachs LB. Group psychotherapy as an aid in the medical treatment of eczema. J Am Acad Dermatol 1988; 18: 286-91.

[48] Grandfield T, Thompson A, Turpin G. An attitudinal study of responses to dermatitis using the implicit association test. Poster presented the Annual British Psychological Society Conference, Cardiff, April 2004. 